\title{
3 Research Square

\section{Dehydration Alters Behavioral Thermoregulation and the Geography of Climatic Vulnerability in Amazonian Lizards}

Agustín Camacho ( $\square$ agustin.camacho@ebd.csic.es )

University of São Paulo

Tuliana O. Brunes

University of São Paulo

Miguel Trefaut Rodrigues

University of São Paulo

\section{Research Article}

Keywords: dehydration, lizards, voluntary thermal maximum, climatic vulnerability, climate warming, Amazon basin, thermal tolerance

Posted Date: April 15th, 2021

DOl: https://doi.org/10.21203/rs.3.rs-394961/v1

License: (c) (i) This work is licensed under a Creative Commons Attribution 4.0 International License. Read Full License 


\section{Abstract}

Since high temperatures and low water availability often strike organisms in parallel, observing how they behaviorally thermohydroregulate may help us to better understand their climatic vulnerability. This understanding is especially important for tropical lizards, purportedly under greater climatic risk. We observed the influence of hydration level on the Voluntary Thermal Maximum (VTM) of two small amazonian lizard species: Loxopholis ferreirai (semiaquatic and scansorial) and Loxopholis percarinatum (leaf litter parthenogenetic dweller), accounting for several sources of variation (turn, body weight, start temperature and heating rate). Then, we used two modelling approaches (simple mapping of thermal margins and NicheMapR), to examine the effects of dehydration, decrease in rainfall, ability to burrow, and tree cover availability, on the geography of climatic vulnerability. Dehydration decreased the VTM in both species, which also reacted to start temperature and heating rates. Our two modelling approaches show that dehydration, changes the intensity, extent and duration of thermal risk across the Amazon basin. Based on our results and previous studies, we identify new evidence needed to better understand thermohydroregulation and model the geography of climatic risk, more realistically.

\section{Introduction}

State-of-the-art protocols to model the geography of habitat suitability and species climatic vulnerability rely on experimental estimations of their thermal tolerance, thermoregulatory behavior and water loss 1,2 . However, for necessary simplification due to data availability, these traits have been mostly considered as fixed for species ${ }^{3-5}$. Notwithstanding, thermophysiological performance is dynamic and not only changes with temperature (Ex. thermal reaction norms) but also with hydration level. Dehydrated animals (ex. herps), exhibit lower critical thermal maxima the high temperature that blocks locomotion ${ }^{6-8}$ and the thermal optima for sprint speed ${ }^{9}$. Further, when combined, heat stress and dehydration may impair ectotherms' growth rates, reproduction and survival ${ }^{10,11}$.

Animals control their body temperature and water in an integrated manner ${ }^{12}$. For instance, dehydrated animals accept being exposed to higher temperatures before panting or making cooling urination at higher temperature when dehydrated (Ex. mammals, chickens, Amphibolorus barbatus, Gila monsters ${ }^{13-}$ ${ }^{18}$ ). Notwithstanding, these may constitute more of emergency responses, rather than a mechanism for frequent thermoregulation (reviewed in Tattersall et al ${ }^{19}$ ). Other dehydrated herp species lower their mean body temperatures in laboratory thermal gradients $7,11,20-22$, while dehydrated endotherms may sometimes allow their body temperatures to raise ${ }^{17}$. Preferences for lower temperatures is often associated to the use of sheltering microhabitats ${ }^{11,22}$, potentially making water a stronger determinant of habitat use and activity time than temperature ${ }^{23,24}$. Given the difficulties of understanding the effects of dehydration on thermoregulation, studying species' responses to evade both, thermal and water stress should simplify the problem. 
The voluntary thermal maximum might offer this possibility. Despite this is one central trait for mechanistic models of daily activity in ectotherms ${ }^{25}$, used to estimate climatic vulnerability ${ }^{26}$, the voluntary thermal maximum (VTM) remains relatively unstudied as a thermal tolerance parameter. In the field, this temperature induces animals to seek retreat ${ }^{6}$, and exposure to it can kill in a matter of hours ${ }^{27}$. This means that whenever the minimum temperature available for a population reaches its VTM, the body temperatures of individuals would also rise dangerously close to their thermal limits. Also, individuals not perfectly sheltered might have these limits overwhelmed. Both inter and intraspecific variation in the VTM are scarcely explored. So far, studied active thermoregulator species (Ex. Phrynosomatidae lizards) have shown the VTM can be geographically invariant across populations separated by millions of years ${ }^{28}$, and unresponsive to changes in oxygen concentration ${ }^{29}$, or to typical experimental conditions of thermal tolerance assays, like heating rates and start temperatures in active thermoregulators ${ }^{30}$. Notwithstanding, typical thermoconformers (Ex. the lizard Hemiergis peronii) do respond to them, making them thus important factors to control for. Effects of dehydration and starvation on the VTM have been absent in studied lizards, although this parameter may vary after injection of saline solutions ${ }^{14}$.

Combining thermal tolerance traits, like the VTM, with environmental temperatures, researchers can obtain several measures of thermal risk ${ }^{1}$. One represents the magnitude of thermal risk, often called thermal safety margins ${ }^{31}$. This metric shows the difference between maximum environmental temperatures experienced by a species and its upper thermal tolerance. Another is the exposure to thermal risk, namely, how much of a species geographic range is hit by negative margins, or the time during which stressful events are occurring at each site. The temperature of the air in the shade has been considered as the minimum temperature available for a dry skinned ectotherm ${ }^{32}$. Yet, small ectotherms might still bury within moist microhabitats and experience lower maximum temperatures ${ }^{33}$, making it important to evaluate how changes in thermal tolerance (Ex. in the VTM), and in the availability of such microhabitats, might alter our estimations of climatic vulnerability. Thanks to mechanistic models of heat and water exchange between individuals and their environment (Ex. the Niche Mapper ${ }^{26}$ ), researchers can simulate the effects changes in the availability of sheltered microhabitats (Ex. underground or under tree cover) and other conditions, to make such evaluations. Among climatic conditions, rainfall may have special importance on thermal vulnerability-it not only damps daily thermal oscillations ${ }^{33}$, but also determines the availability of moisture and water for animals, potentially affecting dehydration rates, thermal tolerance, and the risk of exposure to extreme environmental temperatures.

The lack of relevant data on thermohydroregulation makes field studies necessary to collect them, especially in the tropics, where many species are considered thermoconformers, and subjected to higher thermal risk ${ }^{31,34-36}$. Herein, during a faunal inventory to the Amazon basin, we tested whether dehydration lowers the VTM of two small thermoconformer lizard species, from central Amazonia (Loxopholis ferreirai and Loxopholis percarinatum. Fig 1). Later, we illustrated how changes in the VTM, in the available soil depth for burying, in tree cover, and in rainfall, might alter the geography of thermal risk for the more widely distributed L. percarinatum, across the Amazonian Basin. 


\section{Results}

\section{Effects of hydration level and experimental factors on the VTM}

For both species, only the addition of hydration level, start temperature and heating rate led to successive improvements of model fit (Table S1). Thus, turn and body weight were excluded from the final model before estimating the effects of the other parameters.

For Loxopholis ferreirai, the VTM ranged from 24.1 to $33.3^{\circ} \mathrm{C}(\mathrm{N}=9)$ and was significantly affected by hydration level, heating rate and start temperatures. VTM increased at an average of $0.12{ }^{\circ} \mathrm{C}$ per percentual unit in hydration level $(95 \% \mathrm{Cl}: 0.01-0.22)$. For hydrated lizards $(>95 \% \mathrm{HL})$, the median VTM was $32.8^{\circ} \mathrm{C}$ and the median body weight was 0.694 . For dehydrated lizards ( $<95 \% \mathrm{HL}$ ) the median VTM was $29.2^{\circ} \mathrm{C}$ and the median body weight was 0.671 . The VTM increased an average of $0.77^{\circ} \mathrm{C}$ per ${ }^{\circ} \mathrm{C}$ increase in the start temperature $(95 \% \mathrm{Cl}: 0.40-0.77)$, and also increased $2.3^{\circ} \mathrm{C}$ per degree/minute increased in heating rates (95\% Cl: 0.50-4.2), respectively. See Fig. 2 and Table S2A. Results after applying rankit function for normalization of residuals led to similar conclusions for this species (Table S2B).

Among Loxopholis percarinatum, the VTM ranged from 24.1 to $33.3^{\circ} \mathrm{C}(\mathrm{N}=19)$ and was again significantly affected by hydration level, heating rate and start temperatures. The VTM increased an average of $0.12{ }^{\circ} \mathrm{C}$ per percentual unit in hydration level $(95 \% \mathrm{Cl}$ : $0.05-0.18)$. For hydrated lizards $(>95 \%$ $\mathrm{HL}$ ), the median VTM was $31.2^{\circ} \mathrm{C}$ and the median body weight was $0.628 \mathrm{~g}$. For dehydrated lizards $(<95 \% \mathrm{HL})$ the median VTM was $28.8^{\circ} \mathrm{C}$ and the median body weight was $0.525 \mathrm{~g}$. Increasing start temperature and heating rate again significantly increased the lizards' VTM. The VTM increased an average of $0.41^{\circ} \mathrm{C}$ per ${ }^{\circ} \mathrm{C}$ increase in the start temperature (95\% Cl: $\left.0.12-0.70\right)$, and also increased $0.58{ }^{\circ} \mathrm{C}$ per degree/minute increased in heating rates (95\% Cl: 0.08-1.09), respectively. See Fig. 2 and Table S2C. Results after applying rankit function for normalization of residuals led to similar conclusions for this species (Table S2D).

\section{Maps of thermal risk across the Amazon basin}

Our simple mapping approach estimated that, for hydrated L. percarinatum, only $6 \%$ of known populations would be currently under negative thermal margins (Fig. 3A). However, thermal margins became more negative for dehydrated lizards, leading to $87 \%$ of known populations to reach negative thermal margins if they were dehydrated below $95 \%$ of their fully hydrated weight (Fig. 3B).

With respect to the 64 NicheMapR models generated, panels C-F at Fig. 3 illustrate a sample of the most important effects. The extent, the total duration of thermally stressful events, and the percentage of known lizard populations affected by them, were several orders of magnitude more increased by decreases in the VTM, associated to dehydration, than by any other parameter. The amount of rain and the percentage of tree cover follow, in mixed order of importance depending on the metric used. While changing the amount of rain was more important for determining the number of known populations affected by negative margins, the amount of tree cover had larger effect on the extent and duration of 
thermal stress across the Amazon basin (Table 1. Tables S4 and S5 provide full summaries). The ability to bury down to $10 \mathrm{~cm}$ and changes in weight associated to dehydration did not observably affect our thermal risk metrics.

\section{Discussion}

We showed that typical thermoconformer ectotherms (lizards) can actually adjust their VTM with respect to its hydration level in situations of different heating rates and start temperatures, as expected in natural conditions. Start temperatures and heating rates alter the VTM of thermoconformer lizard species, but not in active-thermoregulators (Ex. phrynosomatid lizards ${ }^{30}$ herein), the bullfrog ${ }^{21}$, and leaf-cutting ants ${ }^{37}$, being all measured within similar heating systems. These facts indicate that the VTM should react to yet unknown taxon-specific factors among ectotherms. Considering that the Loxopholis genus inhabits Amazonian forests since at least 10 million years ago ${ }^{38}$, their capacity for behavioral thermohydroregulation does not seem attributable to a recent past history in open habitats.

Future analyses of factors affecting the VTM of ectotherms should help us find intra and interspecific patterns in thermohydroregulation. Intraspecifically, in the absence of anhomeostasis ${ }^{39}$, individuals should respond against deviations from the optimal thermal and hydration levels, and these responses should include behavioral responses, such as, changes in posture, microhabitat use, and/or activity time $^{12}$. Since the VTM can integrate both temperature and hydration level, and induces at least two of these response types ${ }^{25,40,41}$, a lower VTM in dehydrated individuals might persuade them to progressively move to cooler microhabitats, as daily thermal oscillations, often more intense in drier environments, become more likely to overcome their lowered VTMs. Such process may explain several experimental and field observations of microhabitat use during natural droughts of temperate and tropical lizards 11,23,41 (herein). If air temperature in the shade reaches the decreased VTM more often, sheltering, and potentially stopping activity, might be expected. By achieving lower body temperature, ectothermic animals should decrease their rates of body water loss and energy consumption ${ }^{42,43}$, respectively. However, the absolute performance of essential traits, like speed, hearing, digestive and immune efficiency, and the rates of metabolic water production, can decline too (reviewed in ${ }^{12,44,45}$. These multiple effects justify why many ectotherms resort to sheltered inactivity (i.e. aestivation) under extreme heat and drought. Yet, this response may strongly decrease reproductive output during particularly hot and dry years ${ }^{10}$. In sum, the dehydration-induced decrease in the VTM might also trigger the third major thermohydroregulation response out lined by Rozen-Rechels et al. ${ }^{12}$, and have posterior consequences on reproductive output.

Across species, stronger hydric regulation of the VTM could be initially expected for species from hotter and drier habitats, since active-thermoregulators are often found at them. Yet, anecdotally, Heatwole and Firth ${ }^{46}$ already comment on lizards exhibiting lower VTM after summer, and that these changes were lower for species from more humid environments. They attributed these changes to internal rhythms, or of the external environment. Experimental dehydration did not lower the VTM of the desert iguana ${ }^{14}$, nor the maximum preferred temperatures in temperate lacertidae species ${ }^{20}$. The desert iguana still altered its 
VTM in response to the injection of concentrated saline solutions, as expected for changes in hydration level. Thus, the authors proposed that desert lizards might have especially efficient ways to keep ionic balance under heavy loses of body water, like salt glands, renal secretions, and water stored in their thick tails $^{14}$ (references therein). Besides, these lizards often resort to panting when thermally stressed, which helps cooling down the head ${ }^{47}$ without necessarily retreating from the heat source. Panting is common among lizards from deserts and temperate regions, and panting temperatures may increase when hydration drops ${ }^{13,48}$; reviewed in Camacho and Rusch, ${ }^{48}$ ). Keeping the VTM up might help lizards (and other organisms) behave more flexibly, possibly maintaining water consumption by foraging and keeping physiological performance high (ex. metabolic water production), when cool microhabitats are not available. Such strategy might be especially effective for organisms with large water reserves, stored in their body or tails, and with lower specific water loss rates (Ex. large desert lizards or tortoises ${ }^{39,43,49}$ ). Even from a thermodynamic perspective, the challenges of keeping within specific thermal ranges and hold optimal water levels should also be especially important for smaller ectotherms ${ }^{50}$, like the lizards studied herein (range: 0.21 to $1.23 \mathrm{~g}$ ). Notwithstanding, the commonly shorter life-span of smaller reptiles $^{51}$ (Castanet 1994) might impose special pressures on keeping activity levels.

Ectotherms and endotherms may apply opposite behavioral thermoregulation strategies to avoid water loss. When dehydrated, endotherms often allow to raise their body temperature, following hypothalamic signals ${ }^{15}$ that also lead to stop sweating and panting responses (Ex. chickens ${ }^{16}$; mammals ${ }^{17}$ ). The different strategies may be caused by the disproportionately large maximal mass-specific rates of water loss caused by evaporative cooling of endotherms, compared to ectotherms. These opposite strategies grant further exploration of the links between thermohydroregulation and traits such like body size, metabolic rate, water loss rates, and activity.

Further, maintaining high temperatures may be especially important at places with short seasons for growth and reproduction (Ex. deserts, mountain, and temperate species). In contrast, at tropical rainforests, and particularly for parthenogenetic ectotherms, like $L$. percarinatum, which reproduce almost year-round ${ }^{52}$, waiting for the rain at a cooler refuge in the forest should be less problematic. Doing this should help avoiding the important increases in thermal risk that may ensue decreases in rain, and more long-term reductions in shade, as suggested by our geographic models (Fig. 3). Microhabitat use might also induce interspecific variation in the coupling of the VTM and hydration rate. In our study, the rates of change in VTM per unit in hydration level were $20 \%$ on average more intense for $L$. ferreirai compared to the $L$. percarinatum complex. The somewhat greater reactivity of $L$. ferreirai might be expected for a species that can dehydrate and rehydrate faster. That agrees with the ecology of $L$. ferreirai, which climbs branches of flooded forests ${ }^{53}$, where the environment is more desiccating than at the forest's leaf litter ${ }^{54}$, but grants quick water access. Still, two species comparisons do not allow to infer causality on the divergences found among them ${ }^{55}$, nor is the purpose of this study. Further, the fact of $L$. percarinatum be a complex, composed of $2 \mathrm{n}$ and $3 \mathrm{n}$ lineages with cryptic diversity, and a not yet described bisexual species ${ }^{56}$, makes even harder to compare it with $L$. ferreirai. Future studies might detect more subtle differences in the VTM, unobservable at present, associated to ploidy or parthenogenetic reproduction, as 
seen for other traits among parthenogenetic lineages of geckos ${ }^{57}$. Actually, in the light of such genetic diversity within our study lizards (see methods), our results reaffirm the idea of a general effect of dehydration, lowering the VTM, and potentially narrowing the activity window, among these lineages.

Based on these discussed facts, we propose that the VTM of lizards, and possibly other ectothermic species, may be relatively more reactive to dehydration when the measured species: 1) present less effective mechanisms for controlling plasma osmolality, 2) lack important water reservoirs in their body (i.e. very thick tails, large bodies), 3) lose body water faster, 4) have easier access to cool and humid microhabitats, 5) inhabit places where growth rates do not need to be maximized (i.e. thermally stable and humid), or 6) present sexual reproduction.

Testing these hypotheses will help adding dehydration-induced variation in thermal tolerance to models of climatic risk. The large effects that these changes had on the geographic models of thermal risk identify a new relevant facet to the problem of accounting for water availability (ex. rainfall) and thermohydroregulation when modelling climatic vulnerability ${ }^{24,58}$. The lack of congruence between the risk maps produced by both approaches is expected - apart from measuring relatively different things (Ex. intensity versus duration of exposure), the NicheMapR uses many more parameters than simple mapping, and some impacted the geography of thermal risk (i.e. rainfall and tree cover), although in relatively lower magnitude. The ability of lizards to bury down to $10 \mathrm{~cm}$, while able to provide large thermal protection for related lizards in dry tropical habitats ${ }^{59}$, showed relatively low importance among the factors compared herein. Lower soil moisture has been found to either decrease $\mathrm{s}^{33}$ or increase $^{60}$ the intensity of underground thermal gradients. Such context-dependency, or perhaps a general excess of rainfall, might explain why the parameter "percentage of evaporating surface", did not have clear effects on thermal risk maps. In any case, further studies are needed to better understand thermoregulation options offered by burying behavior and soil moisture. We interpret the combined output of our models as clear warnings that water shortages across the amazon basin will dramatically increase thermal risk for dehydrated leaf litter lizards, but that the output may largely depend on local vegetational responses to changes in climate. In conclusion, data on patterns of species' thermohydroregulation, aestivation, and field evaluations of presence in regions were models give opposite predictions, are badly needed before we can predict impacts of changes in the hydrothermal environment (ex. through climate change, forest fires, or deforestation) on animal populations. Given that, researchers should not spare efforts to raise this information.

\section{Method}

\section{Species accounts and obtention of specimens}

Our two studied species belong to the Gymnophthalmidae. A family older than $50 \mathrm{MY}$ and mostly composed by leaf litter forest species ${ }^{38}$, often considered thermoconformers ${ }^{34,36}$. Loxopholis ferreirai, is a semiaquatic and scansorial lizard who lives over and within logs at flooded "Igapó" forests across the course of the Rio Negro and tributaries ${ }^{53}$. Our second species is Loxopholis percarinatum a 
parthenogenetic leaf litter species, typical of central Amazonian "terra firme" forests ${ }^{56}$. As inhabitants of some of the most thermally stable and humid microhabitats on land (i.e. Amazonian leaf litter and Igapós), these lizards have been regarded as behaviorally insensitive to changes in the thermal environment ${ }^{4,31,34}$.

Our dataset consists of nine adults L. ferreirai and 19 L.percarinatum, including only females (it is a parthenogenetic species' complex). Sizes for this species varied from almost newborn size to adult (see individuals' descriptions at the supplementary file). All collected during a faunal inventory at the Rio Negro, in April 2018 under the license number (SISBIO 30309-11). Thus, most L. ferreirai come from Igapós near to Boa Vista. Igapós are forests typical from Amazonian rivers, which experience seasonal floods. In turn, L. percarinatum were collected at Boa Vista, at terra firme forest, within the Parque da Neblina National Park, and at stretches of land in the west margins of the Rio Negro, across $500 \mathrm{~km}$ from the park to Novo Airão (see georeferenced localities in the supplementary file).

\section{Experimental procedures}

We measured lizard's VTM three times per individual: one within $48 \mathrm{~h}$ after capture, as collected, another time after dehydrating them for one night (8h), and once again after rehydrating them for more $24 \mathrm{~h}$. Heretofore, we will refer to these turns as fresh, dehydrated and rehydrated, respectively. This repeatedmeasures procedure has been shown to detect small variations in the VTM of lizards with similar sample sizes $^{30}$.

\section{Manipulation of lizards' hydration level}

To dehydrate Loxopholis lizards (range: $0.25-1.1 \mathrm{~g}$ in body weight), we kept them overnight within individual, hermetic, plastic recipients $(500 \mathrm{ml})$, containing $400 \mathrm{~g}$ of dry rice. Two log box AA inserted within two of these recipients, recorded, every 30 minutes, the temperature and humidity within the desiccating recipients (total range: $22.9-27.8 \mathrm{C}^{\circ} ; 62.4-81.2 \%$ ). This means that specimens were first measured during the morning of the first day, introduced in the desiccating recipients between $23 \mathrm{PM}$ and $1 \mathrm{AM}$ the previous night day, and measured within 7- 9:30 AM, the following morning.

After measuring their VTM for the second time, lizards were taken back to their recipients, but now containing paper towels soaked with water. That procedure often allowed to rehydrate lizards to hydration levels higher than when they were collected. Then, they had their VTM measured again, in the morning of the third day of the procedure.

To avoid the assumption that freshly captured lizards, or rehydrated lizards, were at their fully hydrated state, we simply considered their maximum weight obtained across the three measurements, as the fully hydrated weight. Therefore, the hydration level for each individual and turn (fresh, dehydrated, and rehydrated) is herein estimated as the percentage of the maximum weight measured for each individual ${ }^{7}$. At each turn, lizards were weighted using a digital balance (precision $0.001 \mathrm{~g}$ ), right before being heated. 
Each day, recipients were searched for defecation and for the two cases where there were excrements, the individuals were discarded from the sample analyzed herein.

\section{Measurement of the voluntary thermal maximum}

Lizards were heated following the protocol evaluated by Camacho et al. ${ }^{30}$. In brief, each individual was placed within a half-closed $400 \mathrm{ml}$ metallic can to warm it up. Before heating, lizards were left for a couple minutes to assess whether they were willing to abandon the can or if they take it as a refuge. This procedure led to excerpt two individuals. Then, lizards were homogeneously heated by external flexwatt $\circledast$ tape, wrapped around the sides and the bottom of the cans, until the animals exited them. Controlling start temperatures and heating rates at a fluvial boat is technically difficult. Therefore, we opted to allow them vary, register their variation (heating rates: $0.12-3.7^{\circ} \mathrm{C} / \mathrm{min}$; start temperature: $22.5 \sim 29.8^{\circ} \mathrm{C}$, see correlation among them in Table S2A), and account for them during the statistical analyses.

The VTM was measured as the dorsal temperature, right over the shoulders of lizards, and just at the moment lizards had that body part outside the can. Body temperature was measured with the "pointer" tool of a C2 FLIR camera, set to $20 \mathrm{~cm}$ distance and 0.80 reflectivity. That set up gave below $0.6^{\circ} \mathrm{C}$ error when comparing the temperature measured by the pointer and a $\mathrm{T}$ thermocouple pressed against the lizards' skin. This procedure was repeated for both species (see supplementary file). Heterothermy (gradients in the temperature of different body parts) was evaluated by Camacho et al. ${ }^{59}$, for an identical heating container and similarly shaped and sized lizards, relatives of Loxopholis. It can be considered as nonexistent. All procedures were approved by the ethic committee of the São Paulo University (protocol: 318/2018). All methods were carried out in accordance with relevant guidelines and regulations. the study was carried out in compliance with the ARRIVE guidelines.

\section{Analyses}

\section{Effect of dehydration and experimental parameters on the VTM}

We used the Akaike's information criterion (AIC), to select among six fitted mixed linear models. In these models, the VTM was sequentially predicted by hydration level and other factors: turn, start temperature, body size, and heating rate. We used lizards' identification numbers as grouping factor to account for repeated measures. In this way, each specimen works as a reference for itself across measurement turns. This allows controlling for interindividual variation in responses and increase the test's sensitivity ${ }^{30}$. In addition, our analysis also accounts for factors which are difficult to control experimentally in field studies, such as: the temperature for start heating, the heating rate, specimens' body size, and the measurement order (i. e. whether lizards showed higher or lower VTMs as a result of repeating the same experiment).

After selecting the predictive factors that most decreased the AIC of the model, we assessed their particular effect of each factor based on the effect size and p-values obtained by the Kenward-Roger method. We also provide confidence intervals for fixed and random effects. Since these approaches 
suggest the same conclusion for our two studied species, we hope to attend reviewers and readers from different statistical schools.

L. percarinatum represents a complex of cryptic hybridizing lineages with different ploidy levels (Brunes et al. 2019). It was not possible to identify ploidy level for most individuals of this study, nor observable differences were attributable to ploidy for the few individuals with such information, or to sampling site (See supporting information file, data). Despite our results were very consistent and show clear effects, further studies can analyze effects of ploidy or geographic variation on our observed relationships, though.

We performed all the analyses in R language (Vr. 4.0 R Core Team 2020; using "Imer" function for fitting mixed models; from the Ime4 package ${ }^{61}$. We observed slight deviations from normality in the model's residuals for $L$. ferreirai species. In this case, applying rankit transformation ${ }^{62}$ to the response variable solved the issue and rendered similar conclusions. For easiness of interpretation, we kept the untransformed results in the manuscript, results under rankit transformation can be consulted at Table S2B.

Mapping potential effects of dehydration on the geography of thermal risk across the Amazonian basin.

We do not wish to provide a prediction of climatic vulnerability for the two species because we do not think reliable ones can be yet provided. Instead, we want to illustrate how dehydration may alter geographic models of thermal risk. We generated these models based on the VTM of hydrated and dehydrated lizards of the L.percarinatum species only.

We used two approaches to obtain complementary information. First, following methods in Recoder et al. 41 , we used a "simple mapping" approach, to map the geographic extent and magnitude of thermal margins ${ }^{31}$ for all pixels of a raster file. This file's pixels represent averaged yearly maximum temperatures, measured in the shade (named bio 5 in the CHELSA database ${ }^{63}$, resolution: $30 \mathrm{sec}$, across the Amazon basin. Despite interpolated air temperatures cannot describe the full thermal heterogeneity at the lizards' scale, and averages of the maximum temperatures do not show the full range of air thermal variation, we assumed that populations at pixels where air temperatures reach the VTM, on average, would be thermally vulnerable. We purposely chose the median value to represent the populational VTM. In that way, the warming tolerance margins calculated as VTM-Tenv would relate to half of the population of lizards. With this approach, we created two maps, one with the median VTM obtained from lizards over $95 \%$ of their fully hydrated weight, and another for the VTM of individuals dehydrated below the $95 \%$ of their fully hydrated weight.

In our second approach, we tried to obtain information on the geographic extent and duration of thermal stress due to dehydration, and also accounting for behavioral thermoregulation. For that, we used the Niche Mapper ${ }^{26}$ to estimate the extent (how many localities) and duration ( how many hours per year) the minimum attainable body temperatures would trespass the VTM, across the amazon's basin. This 
algorithm uses heat and water transfer equation to translate climatic conditions into microclimatic conditions experienced by an animal of certain shape, size and color, at different heights and soil depths, at a spatial resolution of centimeters ${ }^{26,64}$. This approach thus allows a more accurate estimation of the body temperatures of small lizards protected underground in moist environments. In this study, we applied this algorithm for each raster cell of five-minute resolution, all across a shape of the Amazon basin (source: http://worldmap.harvard.edu/geoserver/). Doing it for each 30 seconds cell of the CHELSA database would demand prohibitive calculation time.

To gauge the importance of changes in thermal risk derived from changes in the VTM from changes in environmental conditions related to water availability, we altered the value of the VTM and of several parameters that the NicheMapR uses to calculate body temperatures. Namely: VTM (28.8 vs 31.2 , corresponding to dehydrated vs hydrated lizards), body weight ( 0.525 vs 0.628 , likewise), the amount of surrounding surface that evaporates water ( 0 vs 100), the maximum depth to which the animal can bury ( 0 vs $10 \mathrm{~cm}$ ), the amount of rainfall ( $50 \%$ of current amount vs the current amount), and the maximum percentage in tree cover ( 80 vs $100 \%$ ). We also fed the models with critical thermal maxima and preferred temperatures of $L$. percarinatum estimated by Diele-Viegas et al. ${ }^{65}$. Across all models, "virtual" lizards had access to at least a minimum shade typical from a Brazilian rainforest ${ }^{66}(70 \%)$. For all the other parameters, we used the lizard's default in NicheMapR (see Table S8). Although NicheMapR can simulate the water budget of the lizards, we did not do that because it would require using data that we do not have, like the percentage of fully hydrated weight at which lizards become inactive. Since we did not wish to estimate if lizards would die from surpassing the critical thermal maximum, we did not alter the value of the critical thermal maximum and requested the model not to stop calculations if that value was exceeded. The resulting 64 maps are provided at the supporting online file "Maps". We acknowledge that changing these factors with different magnitudes might result in different maps too. We simply try to show that dehydration induced changes in the VTM and related environmental parameters should affect the geography of thermal risk.

We formally compared the importance of these different parameters on the extent and duration of predicted thermal risk, and of the percentage of populations affected by it across the different maps generated by altering the aforementioned parameters. For this, we fitted three separated generalized least squares models using the parameters as predictive factors. We used the gls function from the package $n \mathrm{me}^{67}$, in R language ${ }^{68}$. Scripts of all the tests and graph shown herein are provided within the supporting information file (Tables S9 and S11).

\section{Declarations}

\section{Acknowledgements}

We are grateful to Camila Moreira, Ivan Prates, José Cassimiro, José Mário Ghellere, Marco A. de Sena, Renato Recoder, and Sergio Marques-Souza for helping at the Rio Negro's expedition in 2018. Kátia Pellegrino, Camila Moreira e a Gabriela Farias for providing ploidy level data. Sergio Marques-Souza 
identified the species. Marco Antônio Marques de Souza assembled the solar energy system used to allow experiments to be carried out on the boat. This work was supported by the Fundação de Amparo à Pesquisa do Estado de São Paulo (FAPESP), processes 2016/03146-4 (TOB) and 2011/50146-6 (MTR); Conselho Nacional de Desenvolvimento Científico e Tecnológico (CNPq), process 301778/2015-9 (MTR); Coordenação de Aperfeiçoamento de Pessoal de Nível Superior/Programa Nacional de Pós Doutorado (CAPES/PNPD) fellowship \#code: 0001 and Marie Curie Grant (897901) (ACG).

\section{Author contributions}

ACG: idea, project preparation, equipment, specimen collection, experiments, analyses and writing, TB: project preparation, equipment, specimen collection and writing, MTR: operational coordination of field work and writing.

\section{Data availability statement}

The dataset, supporting material and scripts to perform the analyses will be deposited in figshare along with the acceptation of this manuscript.

\section{Competing Interests Statement}

The authors are not aware of any conflict of interest.

\section{References}

1. Williams, S. E., Shoo, L. P., Isaac, J. L., Hoffmann, A. A. \& Langham, G. Towards an integrated framework for assessing the vulnerability of species to climate change. PLoS Biol.6, 2621-2626 (2008).

2. Kearney, M. \& Porter, W. Mechanistic niche modelling: combining physiological and spatial data to predict species' ranges. Ecol. Lett.12, 334-350 (2009).

3. Deutsch, C. A. et al. Impacts of climate warming on terrestrial ectotherms across latitude. Proc. Natl. Acad. Sci. U. S. A.105, 6668-6672 (2008).

4. Sinervo, B. et al. Erosion of lizard diversity by climate change and altered thermal niches. Science328, 894-899 (2010).

5. Comte, L. \& Olden, J. D. Climatic vulnerability of the world's freshwater and marine fishes. Nat. Clim. Chang.7, 718-722 (2017).

6. A preliminary study of the thermal requirements of desert reptiles. Bulletin of the American museum of natural history, volume 83: Article 5. Raymond Bridgman Cowles, Charles mitchill Bogert. Q. Rev. Biol.20, 170-170 (1945).

7. Anderson, R. C. O. \& Andrade, D. V. Trading heat and hops for water: Dehydration effects on locomotor performance, thermal limits, and thermoregulatory behavior of a terrestrial toad. Ecol. Evol.7, 9066-9075 (2017). 
8. Plummer, M. V., Williams, B. K., Skiver, M. M. \& Carlyle, J. C. Effects of Dehydration on the Critical Thermal Maximum of the Desert Box Turtle (Terrapene ornata luteola). J. Herpetol.37, 747-750 (2003).

9. Prates, I., Angilleta, M. J., Wilson, R. S., Niehaus, A. C. \& Navas, C. a. Dehydration hardly slows hopping toads (Rhinella granulosa) from xeric and mesic environments. Physiol. Biochem. Zool.86, 451-457 (2013).

10. Wang, Y., Zeng, Z.-G., Li, S.-R., Bi, J.-H. \& Du, W.-G. Low precipitation aggravates the impact of extreme high temperatures on lizard reproduction. Oecologia182, 961-971 (2016).

11. Lorenzon, P., Clobert, J., Oppliger, A. \& John-Alder, H. Effect of water constraint on growth rate, activity and body temperature of yearling common lizard (Lacerta vivipara). Oecologia118, 423-430 (1999).

12. Rozen-Rechels, D. et al. When water interacts with temperature: Ecological and evolutionary implications of thermo-hydroregulation in terrestrial ectotherms. Ecol. Evol.9, 10029-10043 (2019).

13. Parmenter, C. J. \& Heatwole, H. Panting thresholds of lizards. IV. The effect of dehydration on the panting threshold of Amphibolurus barbatus and Amphibolurus muricatus. J. Exp. Zool.191, 327332 (1975).

14. Dupré, R. K. \& Crawford, E. C., Jr. Behavioral thermoregulation during dehydration and osmotic loading of the desert iguana. Physiol. Zool.58, 357-363 (1985).

15. Doris, P. A. \& Baker, M. A. Hypothalamic control of thermoregulation during dehydration. Brain Res.206, 219-222 (1981).

16. Arad, Z. Thermoregulation and acid-base status in the panting dehydrated fowl. J. Appl. Physiol.54, 234-243 (1983).

17. McKinley, M. J., Martelli, D., Pennington, G. L., Trevaks, D. \& McAllen, R. M. Integrating competing demands of osmoregulatory and thermoregulatory homeostasis. Physiology (Bethesda)33, 170-181 (2018).

18. Davis, J. R. \& Denardo, D. F. The contribution of urinary bladder water to hydrostasis in the Gila Monster (Heloderma suspectum). in INTEGRATIVE AND COMPARATIVE BIOLOGY vol. 44 544-544 (SOC INTEGRATIVE COMPARATIVE BIOLOGY 1313 DOLLEY MADISON BLVD, NO 402, MCLEAN ..., 2004).

19. Tattersall, G. J., Cadena, V. \& Skinner, M. C. Respiratory cooling and thermoregulatory coupling in reptiles. Respir. Physiol. Neurobiol.154, 302-318 (2006).

20. Sannolo, M. \& Carretero, M. A. Dehydration constrains thermoregulation and space use in lizards. PLoS One14, e0220384 (2019).

21. Guevara-Molina, E. C., Gomes, F. R. \& Camacho, A. Effects of dehydration on thermoregulatory behavior and thermal tolerance limits of Rana catesbeiana (). J. Therm. Biol.93, 102721 (2020).

22. Crowley, S. R. The Effect of Desiccation upon the Preferred Body Temperature and Activity Level of the Lizard Sceloporus undulatus. Copeia1987, 25-32 (1987). 
23. Ryan, M. J. et al. Too dry for lizards: short-term rainfall influence on lizard microhabitat use in an experimental rainfall manipulation within a piñon-juniper. Funct. Ecol.30, 964-973 (2016).

24. Caetano, G. H. O. et al. Time of activity is a better predictor of the distribution of a tropical lizard than pure environmental temperatures. Oikos129, 953-963 (2020).

25. Heath, J. E. Behavioral regulation of body temperature in poikilotherms. Physiologist13, 399-410 (1970).

26. Kearney, M. R. \& Porter, W. P. NicheMapR - an R package for biophysical modelling: the microclimate model. Ecography (Cop.)40, 664-674 (2017).

27. Curry-Lindahl, K. Thermal ecology of the tree agama (Agama atricollis) in Zaire with a review of heat tolerance in reptiles. J. Zool.188, 185-220 (1979).

28. Wiens, J. J. et al. Climate change, extinction, and Sky Island biogeography in a montane lizard. Mol. Ecol.28, 2610-2624 (2019).

29. Camacho, A., Vandenbrooks, J. M., Riley, A., Telemeco, R. S. \& Angilletta, M. J., Jr. Oxygen supply did not affect how lizards responded to thermal stress. Integr. Zool.13, 428-436 (2018).

30. Camacho, A. et al. Measuring behavioral thermal tolerance to address hot topics in ecology, evolution, and conservation. J. Therm. Biol.73, 71-79 (2018).

31. Huey, R. B. et al. Why tropical forest lizards are vulnerable to climate warming. Proc. Biol. Sci.276, 1939-1948 (2009).

32. Bakken, G. S. \& Angilletta, M. J., Jr. How to avoid errors when quantifying thermal environments. Funct. Ecol.28, 96-107 (2014).

33. Geiger, R. Climate near the ground. (Harvard University Press, 1966).

34. Vitt, L. J., Avila-Pires, T. C. S., Caldwell, J. P. \& Oliveira, V. R. L. The impact of individual tree harvesting on thermal environments of lizards in amazonian Rain Forest. Conserv. Biol.12, 654-664 (1998).

35. Pontes-da-Silva, E. et al. Extinction risks forced by climatic change and intraspecific variation in the thermal physiology of a tropical lizard. J. Therm. Biol.73, 50-60 (2018).

36. Diele-Viegas, L. M., Werneck, F. P. \& Rocha, C. F. D. Climate change effects on population dynamics of three species of Amazonian lizards. Comp. Biochem. Physiol. A Mol. Integr. Physiol.236, 110530 (2019).

37. Lima, C. S., Frazão, H. A. \& Camacho, A. Integrative responses of leaf-cutting ants to temperature rises. bioRxiv (2020) doi:10.1101/2020.08.04.236844.

38. Recoder, R. et al. Lizards from the Lost World: two new species and evolutionary relationships of the Pantepui highland Riolama (Gymnophthalmidae). Zool. J. Linn. Soc.190, 271-297 (2020).

39. Peterson, C. C. Anhomeostasis: Seasonal water and solute relations in two populations of the desert tortoise (Gopherus agassizii) during chronic drought. Physiol. Zool.69, 1324-1358 (1996).

40. Ruibal, R. Thermal relations of five species of tropical lizards. Evolution15, 98-111 (1961).

41. Recoder, R. S., Magalhães-Júnior, A. \& Rodrigues, J. Thermal constraints explain the distribution of the climate relict lizard Colobosauroides carvalhoi (Gymnophthalmidae) in the semiarid caatinga. 
South Am. J. Herpetol. (2018).

42. Bennett, A. F. Ventilation in two species of lizards during rest and activity. Comp. Biochem. Physiol. A Comp. Physiol.46, 653-671 (1973).

43. Warburg.M.R. The influence of ambient temperature and humidity on the body temperature and water loss from two Australian lizards, Tiliqua rugosa (Gray) (Scincidae) and Amphibolurus barbatus cuvier (Agamidae). Aust. J. Zool.13, 331 (1965).

44. Huey, R. B. Temperature, physiology, and the ecology of reptiles. in Biology of the Reptilia (Citeseer, 1982).

45. Navas, C. A. \& Carvalho, J. E. Aestivation: Molecular and Physiological Aspects. (Springer, Berlin, Heidelberg, 2010).

46. Heatwole, H. \& Firth, B. T. Voluntary Maximum Temperature of the Jackie Lizard, Amphibolurus muricatus. Copeia1982, 824 (1982).

47. Crawford, E. C., Jr, Palomeque, J. \& Barber, B. J. A physiological basis for head-body temperature differences in a panting lizard. Comp. Biochem. Physiol. A Comp. Physiol.56, 161-163 (1977).

48. Camacho, A. \& Rusch, T. W. Methods and pitfalls of measuring thermal preference and tolerance in lizards. J. Therm. Biol.68, 63-72 (2017).

49. Dupré, R. K. \& Crawford, E. C. Elevation of the panting threshold of the desert iguana, Dipsosaurus dorsalis, during dehydration: potential roles of changes in plasma osmolality and body fluid volume. J. Comp. Physiol. B156, 377-381 (1986).

50. Kearney, M. R., Simpson, S. J., Raubenheimer, D. \& Kooijman, S. A. L. M. Balancing heat, water and nutrients under environmental change: a thermodynamic niche framework. Funct. Ecol.27, 950-966 (2013).

51. Castanet, J. Age estimation and longevity in reptiles. Gerontology40, 174-192 (1994).

52. Dias, D.-M. História natural do lagarto partenogenético Leposoma percarinatum (Squamata: Gymnophthalmidae) em floresta amazônica, Pará, Brasil. (2012).

53. Souza, S. M., de Sena, M. A., Ferreira, G. C., Rodrigues, M. T. \& Brunes, T. O. Natural history notes and range extension of Loxopholis ferreirai (Rodrigues and Avila-Pires, 2005): a micro-endemic species from the flooded igapó forests of Rio Negro and tributaries, Brazilian Amazonia (Squamata: Gymnophthalmidae). Herpetol. Notes13, 235-239 (2020).

54. Tracy, C. R., Christian, K. A. \& Tracy, C. R. Not just small, wet, and cold: effects of body size and skin resistance on thermoregulation and arboreality of frogs. Ecology91, 1477-1484 (2010).

55. Garland, T., Jr \& Adolph, S. C. Why not to do two-species comparative studies: Limitations on inferring adaptation. Physiol. Zool.67, 797-828 (1994).

56. Brunes, T. O., da Silva, A. J. \& Marques-Souza, S. Not always young: The first vertebrate ancient origin of true parthenogenesis found in an Amazon leaf litter lizard with evidence of mitochondrial haplotypes surfing on .... Mol. Phylogenet. Evol. (2019). 
57. Roberts, J. A., Vo, H. D., Fujita, M. K., Moritz, C. \& Kearney, M. Physiological implications of genomic state in parthenogenetic lizards of reciprocal hybrid origin. J. Evol. Biol.25, 252-263 (2012).

58. Kearney, M. R., Munns, S. L., Moore, D., Malishev, M. \& Bull, C. M. Field tests of a general ectotherm niche model show how water can limit lizard activity and distribution. Ecol. Monogr.88, 672-693 (2018).

59. Camacho, A. et al. Interaction of morphology, thermal physiology and burrowing performance during the evolution of fossoriality in Gymnophthalmini lizards. Funct. Ecol.29, 515-521 (2015).

60. Camacho, A., Trefaut Rodrigues, M. \& Navas, C. Extreme operative temperatures are better descriptors of the thermal environment than mean temperatures. J. Therm. Biol.49-50, 106-111 (2015).

61. Bates, D., Kliegl, R., Vasishth, S. \& Baayen, H. Parsimonious Mixed Models. arXiv [stat.ME](2015).

62. Soloman, S. R. \& Sawilowsky, S. S. Impact of rank-based normalizing transformations on the accuracy of test scores. J. Mod. Appl. Stat. Methods8, 448-462 (2009).

63. Karger, D. N. et al. Climatologies at high resolution for the earth's land surface areas. Sci. Data4, 170122 (2017).

64. Kearney, M. R. et al. Microclimate modelling at macro scales: a test of a general microclimate model integrated with gridded continental-scale soil and weather data. Methods Ecol. Evol.5, 273-286 (2014).

65. Diele-Viegas, L. M. et al. Thermal physiology of Amazonian lizards (Reptilia: Squamata). PLoS One13, e0192834 (2018).

66. Guerrero, A. C. \& da Rocha, P. L. B. Passive restoration in biodiversity hotspots: Consequences for an Atlantic Rainforest lizard taxocene. Biotropica42, 379-387 (2010).

67. Pinheiro, J., Bates, D., DebRoy, S. \& Sarkar, D. R Development Core Team (2013) nlme: linear and nonlinear mixed effects models. R package version 3.1-111. (2014).

68. Team, R. C. R: A language and environment for statistical computing. Foundation for statistical computing. (2017).

\section{Tables}

Table 1. Comparison of predicted effects sizes of changing different parameters on the extent (number of sites across the Amazon basin), duration (number of yearly hours over the VTM), and number of known populations affected by thermally stressful events for $L$. percarinatum, across the Amazon's basin. Parameters: Weight= body weight, VTM= voluntary thermal maximum, Moist_surface = percentage of surrounding surface that can evaporate water, Maxdepth = maximum depth to which a lizard can dig, Rain=amount of rain falling, Maxshade = Maximum percentage of tree cover that the lizard has access to. See methods to consult the levels compared among factors. See tables S3, S4, and S5, for full results. 


\begin{tabular}{|lllllll|}
\hline & Extent & \multicolumn{3}{c|}{ Duration } & \multicolumn{2}{c|}{ Populations } \\
\hline & t-value & p-value & t-value & p-value & t-value & p-value \\
\hline (Intercept) & 39.16 & 0.00 & 22.06 & 0.00 & -44.14 & 0.00 \\
\hline Weight_0.628g & -0.13 & 0.90 & -0.02 & 0.98 & -0.09 & 0.93 \\
\hline VTM_31.2C & -32.45 & 0.00 & -21.56 & 0.00 & -52.27 & 0.00 \\
\hline Moist_surface_100\% & -0.09 & 0.93 & 0.04 & 0.97 & 0.28 & 0.78 \\
\hline Maxdepth_10cm & -0.03 & 0.98 & -0.03 & 0.98 & -0.09 & 0.93 \\
\hline Rain_full & -5.34 & 0.00 & 1.44 & 0.16 & -9.68 & 0.00 \\
\hline Maxshade_100\% & -11.42 & 0.00 & -7.54 & 0.00 & -1.93 & 0.06 \\
\hline
\end{tabular}

\section{Figures}

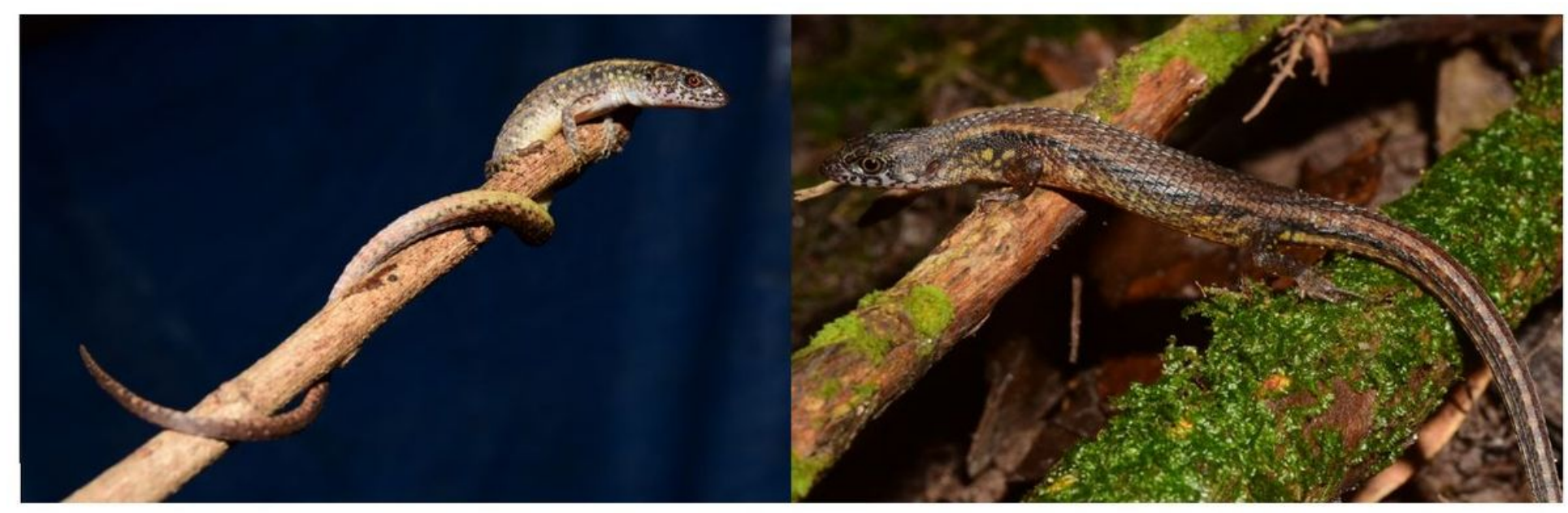

Figure 1

Loxopholis ferreirai (right), showing climbing abilities, and L. percarinatum (left). Pictures by A.C.G. 

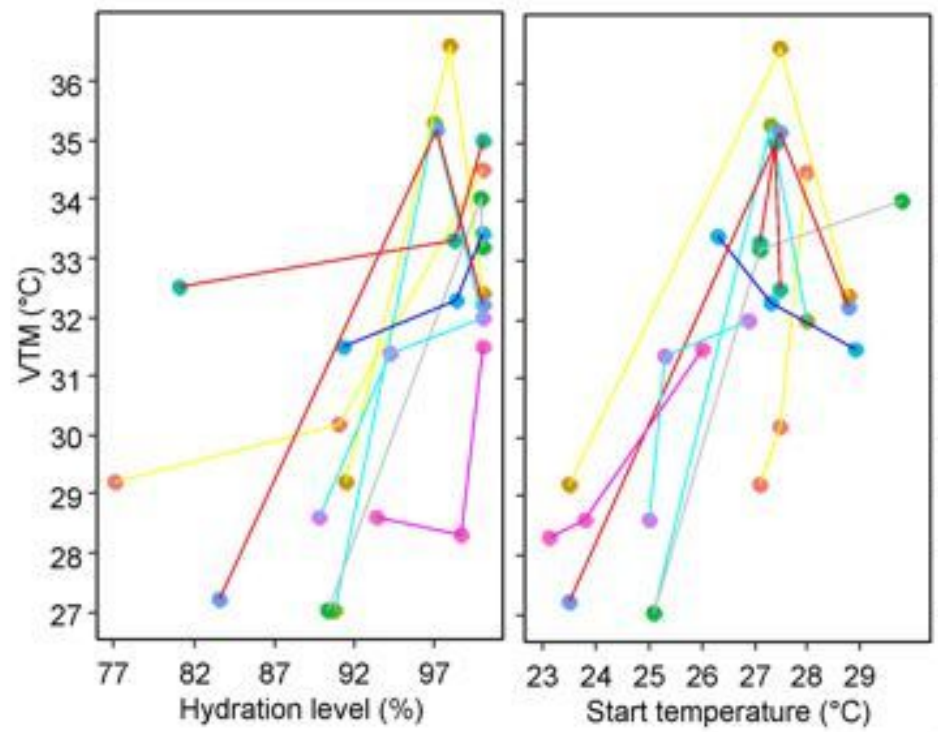

$\begin{array}{lllllll}23 & 24 & 25 & 26 & 27 & 28 & 29\end{array}$

Start temperature $\left({ }^{\circ} \mathrm{C}\right)$
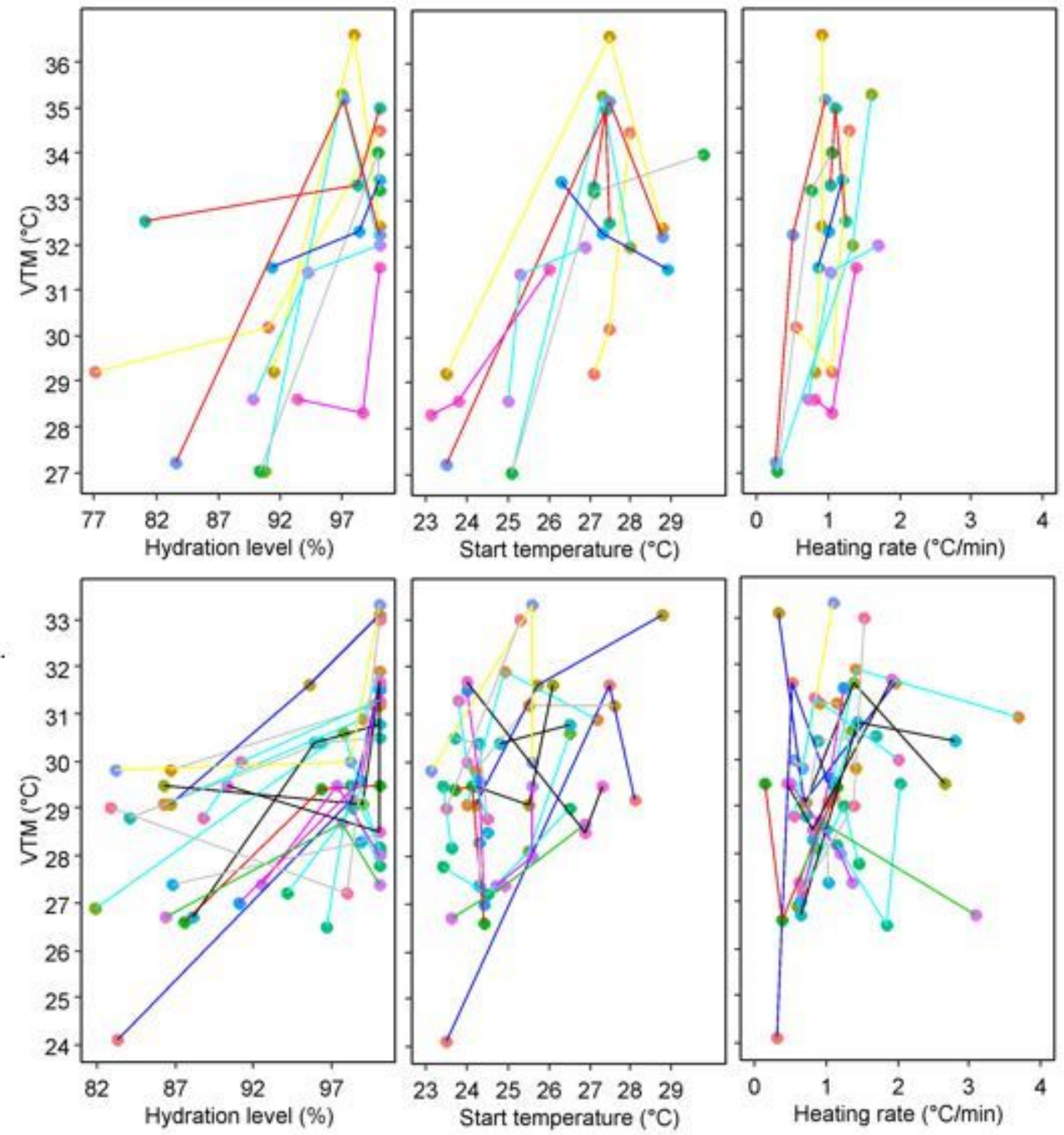

Figure 2

Changes in the VTM associated to hydration level (left), start temperature (center) and heating rate (left) in Loxopholis ferreirai (upper row) and L. percarinatum (lower row) lizards. Each color represents a specimen. Graphs plotting residual values can be viewed in Fig. S2. 

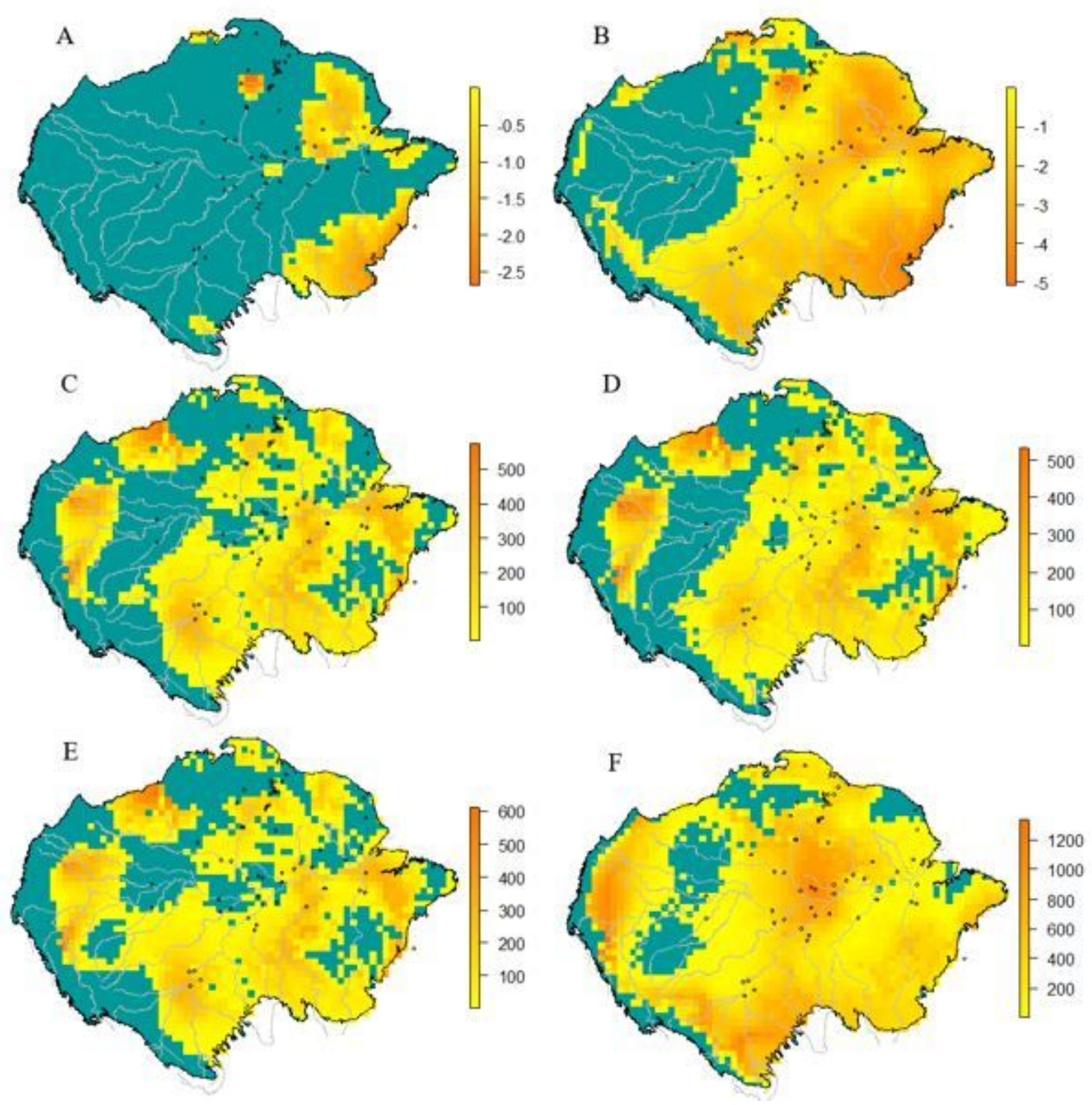

Figure 3

Maps predicting present thermal risk for Loxopholis percarinatum across the amazon basin. Points represent known populations of these lizards. Pixels in yellow to orange represent areas reaching negative thermal margins, while green represents areas where thermal margins remained positive. $A$ and $B$ represent the subtraction of the median VTM of hydrated (A) or dehydrated (B) lizards to the mean of the yearly maximum air temperatures at any pixel. In $\mathrm{C}$ to $\mathrm{F}$, the same colors show the number of hours that body temperatures exceeded the VTM for hydrated and dehydrated lizards when allowed to seek for refuge down to $10 \mathrm{~cm}$ under wet leaf litter in the shade. $C$ represents a situation with hydrated lizards (VTM $=31.2^{\circ} \mathrm{C}$ ), $100 \%$ tree cover, full rain and ability to burrow down to $10 \mathrm{~cm}$, while $\mathrm{D}$ to $\mathrm{F}$ show expected effects of altering some these parameters. D represents thermal risk after a $50 \%$ decrease in rainfall, E shows risk after a decrease of $20 \%$ in tree cover, and F shows risk for lizards with VTM $=28.8$ ${ }^{\circ} \mathrm{C}$, The median VTM for L. percarinatum under $95 \%$ of their maximum hydration level. Note: The designations employed and the presentation of the material on this map do not imply the expression of 
any opinion whatsoever on the part of Research Square concerning the legal status of any country, territory, city or area or of its authorities, or concerning the delimitation of its frontiers or boundaries. This map has been provided by the authors.

\section{Supplementary Files}

This is a list of supplementary files associated with this preprint. Click to download.

- Supplementaryfile.xlsx 